\title{
ONLINE INTERACTION TOOLS: IMPACTS ON STUDENTS' PARTICIPATION AND LEARNING
}

\author{
Mahsa Khalili and Peter M. Ostafichuk \\ Department of Mechanical Engineering, University of British Columbia \\ mahsa.khalili@alumni.ubc.ca
}

\begin{abstract}
Shyness, low self-esteem, and fear of peer/instructor's judgment are among the common factors hindering students' participation (e.g., asking/answering questions) in classrooms. In this regard, anonymous response systems such as iClickers have been used to improve students' engagement in classroom activities. Although iClickers can enhance students' participation, they promote one-way interactions only (i.e., students answering questions). Online interaction platforms are alternatives to traditional clickers that provide more flexibility for students and allow them to answer/ask questions in real-time. In this study, we investigated the use of an online tool that allows for real-time presentation of the lecture's slides integrated with an audience interaction platform for anonymous classroom participation. The findings of our study provide evidence regarding the positive impacts of using this tool (e.g., improved classroom participation through asking questions and voting in polls) in an undergraduate Mechanical Engineering Design course. We discuss the potential improvements that can be made to the implementation of this approach in future courses to enhance students' engagement when using this interactive tool.
\end{abstract}

Keywords: Classroom participation and engagement, anonymous voting, online interaction platform, learning.

\section{INTRODUCTION}

Students' participation and engagement through asking/answering questions in classroom can reinforce their learning process [1],[2]. Findings of previous research across various disciplines have shown that this form of classroom participation is influenced by several factors, such as students' personality [3], gender [4], their cultural and educational background [5], and classroom logistics (e.g., size) [6]. In this regard, shyness, low self-esteem, fear of peer/instructor's judgment, and the feelings of confusion were identified as some of the inhibiting factors for asking/answering questions in classrooms.

One strategy to enhance students' participation in classroom is to use anonymous classroom response systems (CRS) [7]. Results of previous studies on the use of CRS (e.g., iClicker) have shown their positive impact on promoting a sense of comfort, encouraging participation, and motivating students to interact with the subject matter [8],[9]. In addition to this, when using these tools in classrooms, students' participation and engagement were significantly higher compared to conventional classroom settings, where students could only answer questions by raising hands [10],[11].

Although the use of iClickers can enhance students' engagement in classrooms, these devices are quite limited in their function and can be only used for basic classroom interactions. There are other alternatives to traditional clickers, such as online interaction platforms, that can provide all the features of clickers as well as other capabilities [12]. These systems enable instructors to ask questions during their class and students to respond to those questions using their mobile devices (e.g., laptop, tablet, smartphone). Moreover, students can participate in polls, quizzes, surveys, and Q\&As and provide feedback to the instructor in real-time. Compared to clickers, these tools provide more flexibility for students' engagement in classroom activities. Despite their potential positive impacts on classroom participation, only limited studies exist regarding the effectiveness of these online interaction tools on students' learning and classroom engagement [13].

In this work, we investigated the impacts of using an online and anonymous audience engagement platform on class dynamics and participation of students in a third-year Mechanical Engineering Design course at the University of British Columbia (UBC). Moreover, we examined the opinions, perceptions, and evaluations of students about their learning, engagement and participation in classroom activities, as well as their experiences with the online interactive platform.

\section{METHODS}

First, we examined the capabilities and limitations of some of the existing audience response systems, such as Mentimeter [14], Glisser [15], Slido [16], and SlideLizard [17]. Given the adaptability and ease of integration of SlideLizard with the format of the lecture presentation at the time (i.e., PowerPoint slides), we selected this online interaction tool. Next, to assess the effectiveness of using 
this online platform, we developed and used mixedmethods online surveys (including both quantitative and qualitative open-ended questions) and performed classroom observations. This study was approved by the Behavioural Research Ethics Board of UBC.

\subsection{SlideLizard ${ }^{\mathrm{TM}}$ : An Audience Interaction Tool}

SlideLizard (SL) is an all-in-one online tool that allows for seamless and dynamic integration of the lecture's slides with an audience interaction platform for anonymous participation in the classroom. We used SL's PowerPointplugin to integrate the lecture's slides with the online interaction tool to automatically live-share presentation slides as they were presented. Students could access the presentation on their smartphones, tablets, or laptops by using the participation-link shared by the instructor. During the presentation, students could see the slides live as the instructor advanced through the presentation. Moreover, students could use their electronic devices to directly post questions and the instructor could access incoming questions in real-time. The instructor could also administer live polls that had been pre-defined and inserted between slides, allowing for a seamless transfer between the lecture slides and the polls. Live polls were pushed instantly to students' electronic devices, the instructor received poll responses continuously in real-time, and poll results could be shared with the class, directly over the slides. With SL the instructor could stay within PowerPoint the whole time and control polls or Q\&A in the presenter view on the second screen. It is important to emphasize that SL allowed for totally anonymous interactivity during the lectures.

\subsection{Surveys and Classroom Observations}

2.2.1. SL Integration and Survey Administration for Selected Lectures. We used the SL platform in selected 50-minute lectures of a third-year Mechanical Engineering Design course at UBC. The course covers topics in solid mechanics (e.g. fatigue, fracture, deflection) in design contexts. The instructor presented the lecture slides through the SL platform (SL lectures) and integrated polling slides (e.g., students were asked to respond to multiple-choice questions) in the lecture PowerPoint. Moreover, students were encouraged to ask questions both verbally or through the online platform. At the end of these lectures, students were asked to fill out an optional and anonymous survey (SL Survey - Appendix A.1). In this survey, students were asked to (1) rate their level of engagement and participation in the classroom; (2) rate their satisfaction with their engagement and participation in the classroom; (3) rate their overall satisfaction regarding their understanding of the lecture topics; and (4) rate their satisfaction with the format/structure of the lecture. Students responded to each question using a 5point Likert scale.

Other lectures throughout the term were held in a conventional setting (CON lectures), in which students were able to participate in class activities (e.g. asking/answering questions) only verbally. At the end of some of these CON lectures, students were asked to fill out an optional and anonymous survey (CON Survey Appendix A.1) to evaluate and comment on their experience in these lectures using the same questions as the SL survey. Due to drift in the schedule, a few lectures were held in a mixed format (CON-SL lectures), in which part of the lecture was presented in a conventional setting and the other part of the lecture was presented through SL.

2.2.2. First-/Second-Half Surveys. In addition to the $\mathrm{SL} / \mathrm{CON}$ surveys administered at the end of classes, we conducted two surveys to evaluate student's overall engagement in classroom activities in the first half of the course (First-Half Survey - Appendix A.2) and in the second half of the course (Second-Half Survey - Appendix A.2). In addition to the previously explained questions, these surveys contained the following questions: (1) whether students are comfortable with verbally asking/answering questions during the lecture; (2) whether students are comfortable posting questions/answers via the online platform during the lecture; (3) whether the use of this tool had any impact on students' learning and understanding the topic; and (4) whether students recommend the use of this online platform in the future and other courses. These surveys were concluded with an open text entry form provided to the students to comment on the benefits and drawbacks of using SL in selected lectures of this course.

The final versions of all surveys were implemented on Qualtrics [18]. Students had the option to participate or opt out of the surveys. We did not collect any personally identifying data in this study. However, we collected IP addresses to identify potential duplicate entries. Classroom Observation. In addition to conducting the online surveys, one of the course teaching assistants (and the first author of this paper), visited selected CON and SL lectures to observe classroom activities. During these classroom observations, the following was recorded:

- the number of questions verbally asked by students to the instructor,

- the number of questions posted by students to the SL platform (if used that class), and

- students' engagement during the lecture in the form of on-task behaviours and general attentiveness.

Before performing the classroom observations, we announced that participation in classroom activities and recorded observations had no impact on students' final grades. Students and groups were also provided an option to opt out of being observed, but none did. We used IBM SPSS [19] to conduct statistical analyses. 


\section{RESULTS}

Ninety-eight students were registered in the course and, on average, 90 students attended the 7 selected lectures for classroom observations. We used SL in 5 lectures (3 SL lectures: SL1, SL2, SL3 and 2 CON-SL lectures: CONSL1, CON-SL2) and we conducted 3 SL surveys. Moreover, we performed classroom observations for two CON lectures (2 CON lectures: CON1, CON2) and conducted two CON surveys. The timeline of class observations and surveys is shown in Fig. 1.

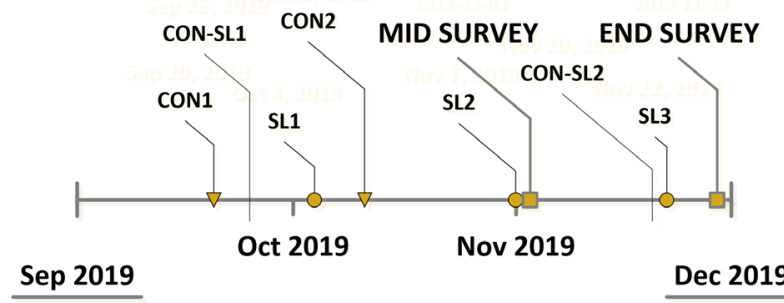

$\square$ Full survey

- SL survey

$\nabla$ CON survey

Fig. 1. Timeline of class observations and surveys

A summary of the data collected during SL and CONSL lectures is presented in Table 1. The percentage of students who used the SL platform (i.e., SL attendees) varied between $30-85 \%$ of the lecture participants throughout the term. However, among the SL attendees, participation in online voting remained in the same range (i.e., $74-79 \%$ ). Classroom participation during the SL, $\mathrm{CON}$, and CON-SL lectures are summarized and presented in Table 2.

Table 1: SL attendance and poll participation during SL and CON-SL lectures

\begin{tabular}{|l|c|c|c|}
\hline $\begin{array}{l}\text { Type of } \\
\text { lecture }\end{array}$ & $\begin{array}{l}\text { No. of } \\
\text { Attendees }\end{array}$ & $\begin{array}{l}\text { No. of } \\
\text { polls }\end{array}$ & $\begin{array}{l}\text { Average } \\
\text { participation (\%) }\end{array}$ \\
\hline CON-SL1 & 76 & 1 & $78 \%$ \\
\hline SL1 & 73 & 3 & $75 \%$ \\
\hline CON-SL2 & 29 & - & - \\
\hline SL2 & 30 & 3 & $74 \%$ \\
\hline SL3 & 27 & 5 & $79 \%$ \\
\hline
\end{tabular}

Table 2: Individual classroom participation during CON, SL, and CON-SL lectures

\begin{tabular}{|l|c|c|c|}
\hline \multirow{2}{*}{ Session } & \multicolumn{3}{|c|}{ Activity } \\
\cline { 2 - 4 } & Verbal Qs $^{1}$ & $\begin{array}{l}\text { One-on-one } \\
\text { Q\&A }\end{array}$ & Online Qs $^{3}$ \\
\hline CON1 & 0 & 3 & N/A \\
\hline CON-SL1 & 7 & 3 & 2 \\
\hline SL1 & 5 & 0 & 8 \\
\hline CON2 & 5 & 7 & N/A \\
\hline SL2 & 1 & 1 & 5 \\
\hline CON-SL2 & 7 & 0 & 3 \\
\hline SL3 & 4 & 1 & \\
\hline
\end{tabular}

${ }^{1}$ The number of questions asked verbally in class
${ }^{2}$ The number of one-on-one conversations with the instructor during the group discussion times

${ }^{3}$ The number of questions asked through the online platform

A total of 27 and 43 students participated in the two CON and the three SL surveys, respectively. Students' responses to survey questions are shown in Fig. 2. On average, students rated their level of engagement in CON lectures slightly higher than in SL lectures (CON/SL-Q1 [mean $\pm \mathrm{SD}]: 2.3 \pm 0.8$ vs. $2.2 \pm 1.0$ ). However, when rating their satisfaction with their level of engagement, on average, students were slightly more satisfied in SL lectures compared to CON lectures (CON/SL-Q2: $3.9 \pm 0.9$ vs. 3.7 \pm 0.9 ). Students found it easier to follow SL lectures compared to CON lectures (CON/SL-Q3: $4.0 \pm 0.9$ vs. $3.5 \pm 1.0$ ) and, on average, they were more satisfied with the format of SL lectures compared to $\mathrm{CON}$ lectures (CON/SL-Q4: $4.1 \pm 0.8$ vs. $3.9 \pm 1.0)$. We performed an independent t-test with a significance level of $p=0.05$ to compare the CON and SL survey responses lectures. The results revealed that there were no statistically significant differences between students' responses to the $\mathrm{CON}$ and SL surveys.

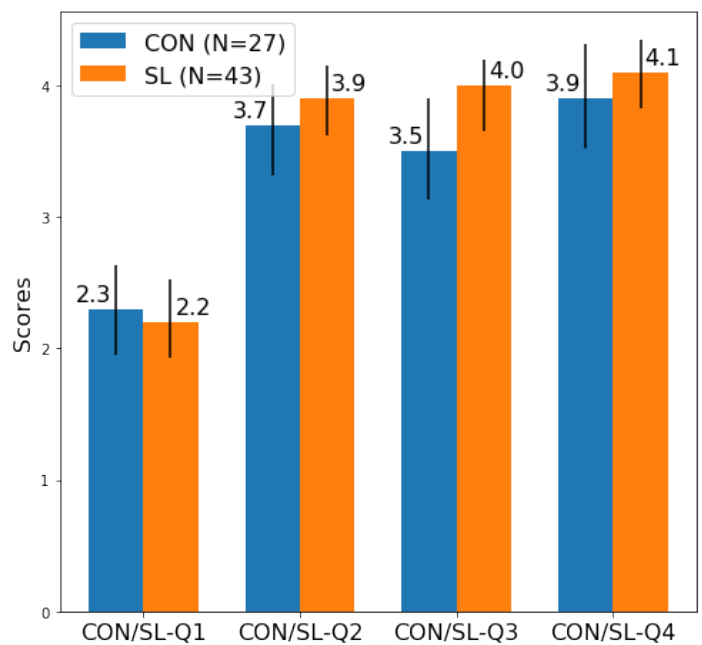

Fig. 2. Student responses to SL and CON survey questions (Error bars are indicating the $95 \% \mathrm{Cl}$ )

We conducted the First-Half survey mid-way through the course and the Second-Half survey after the completion of the last lecture. A total of 15 and 17 students participated in the First-Half and Second-Half surveys, respectively. Students' responses to these surveys are shown in Fig. 3. Survey participants reported higher engagement and participation during the first half of the course compared to the second half (F/S-Q1: $3.5 \pm 0.7$ vs. $2.3 \pm 0.9)$. However, they indicated higher satisfaction with their level of engagement during the second half of the course compared to the first half (F/S-Q2: $4.1 \pm 0.8$ vs. $3.4 \pm 1.2$ ). Regarding understanding the course material, students reported similar satisfaction scores during the first and second half (F/S-Q3). Students indicated being slightly more comfortable verbally asking/answering questions in the 
second half compared to the first half of the course $(\mathrm{F} / \mathrm{S}$ Q4: $3.2 \pm 0.9$ vs. $3.0 \pm 0.9$ ). Similarly, they reported being more comfortable posting questions/answers via the online platform in the second half compared to the first half of the course (F/S-Q5: $3.9 \pm 1.0$ vs. 3.6 \pm 1.0$)$. Our findings reveal that students were consistently more comfortable posting questions/answers via the online tool compared to verbally asking/answering questions throughout the course (F/S-Q4 and F/S-Q5). More than half of the survey participants indicated that SL had positive impacts on their learning (F/S-Q6) and recommended future use of this tool $(\mathrm{F} / \mathrm{S}-$ Q7).

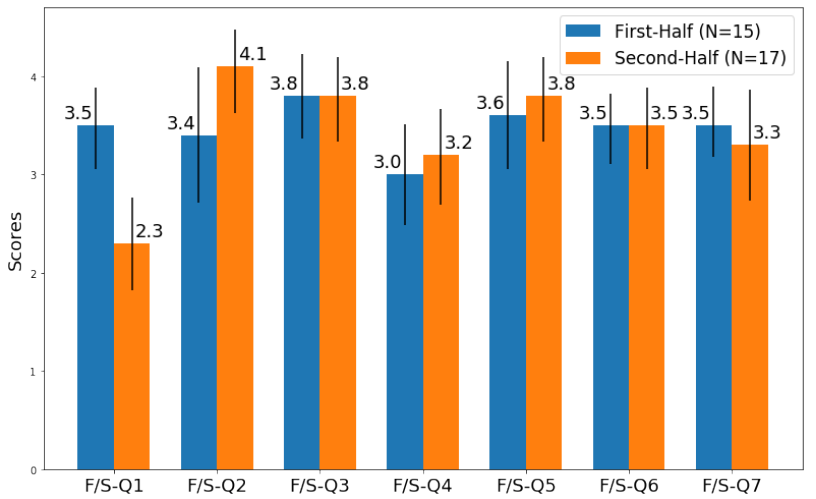

Fig. 3. Student responses to First- and Second-Half survey questions (Error bars are indicating the $95 \% \mathrm{Cl}$ )

Four themes emerged from the analysis of students' comments on the benefits of using SL (F/S-Q8). These themes are presented in Table 3. Several students expressed having a positive experience during SL lectures, examples of which are "It made the class more interesting and engaging. I felt like everyone was participating together and it wasn't just another lecture", and "Dr. Ostafichuk does a great job of making the class comfortable with asking questions and providing ideas, even if you're unsure. SlideLizard is also a good way to ask a question anonymously, if you still have misgivings about asking in front of everyone."

Three themes emerged from students' comments regarding the drawbacks of using $\mathrm{SL}(\mathrm{F} / \mathrm{S}-\mathrm{Q} 9)$ that are presented in Table 4. One student mentioned the fact that the use of the SL platform may discourage organic handsraised question-asking.

Table 3: Students' comments regarding the benefits of using the SL platform

\begin{tabular}{|l|} 
Theme 1: Asking questions \\
\hline - Being able to send questions through SlideLizard \\
anonymously. \\
- Asking questions or answering them without having \\
to speak up in front of the whole class. \\
- Easier for shy people to ask questions.
\end{tabular}

- People felt comfortable asking questions and even if it wasn't me that asked the question, it was a good review of the material so I appreciated the opportunity to hear the question and answer.

- People were more likely to ask questions and this helped everyone because often more than one student was hoping for an answer to the question.

- Nice to hear people's questions and have explanations of each SlideLizard answer.

\section{Theme 2: Participating in polls}

- The multiple-choice polls you could participate in (anonymously) to answer questions.

- I usually do not know the answer. If there are multiple choices I will participate though.

- I really liked being able to participate by voting on questions instead of having to answer out loud.

- It's interesting to answer a multiple-choice question so it forces me to read the material that's on the screen and think about it.

- Polls were good a way to encourage discussion within teams.

\section{Theme 3: Having access to the slides}

- Being able to switch between slides in my own time

- It provides a zoomed-in version of the slides for classrooms that are bigger and harder to see from the back...

\section{Theme 4: Having an iClicker alternative}

- It has iClicker capabilities without having to buy it

- [SL] surveys students without using expensive tools like iClicker

- Cheaper than iClicker so good

Table 4: Students' comments regarding the drawbacks of using the SL platform

\section{Theme 1: Getting distracted}

- People may start playing phones more.

- Puts your phone in your hand which is distracting.

- Being on your phone can distract some students. I have noticed that more students around me are okay with taking their phones out because it can be seen as participating on SlideLizard even if they are actually doing something else on their phones.

- I don't like to use my phone during class and it can be distracting. I will miss what the instructor is talking about while putting down questions. 


\section{Theme 2: Experiencing technical difficulties}

- There is no active writing on the slides by the prof which can make it harder to follow what they are saying.

- Not being able to annotate the slides in the lecture.

- Being stuck on one slide.

- Slides weren't updated in real-time if there are hidden objects

- I didn't like that I couldn't see the current screen when there were added items.

Theme 3: Slowing class flow and off-topic questions

- It could slow class flow. This didn't happen often though.

- If the course is not short in time, SlideLizard can be implemented as a helpful tool.

- Students could ask distracting/irrelevant questions. Dr. Ostafichuk was good with re-focusing the class, though (and sometimes the comic relief was welltimed).

- Off-topic questions/comments

- People can ask random questions

- May be distracting when irrelevant questions are asked.

\section{DISCUSSION}

In this study, we sought to examine the impacts of using an online interaction tool on classroom participation. Classroom observations during the CON lectures and students' comments suggest that the culture of this course (e.g., teaching strategies and lecture formats) was such that several students seemed to be actively engaged and comfortable interacting verbally with the instructor during the lectures. However, similar to the findings of previous research [20], we realized that only a group of students were actively participating in Q\&As during the lectures.

The number of questions asked verbally during the seven observed lectured varied from day-to-day, but, on average, students asked more questions during lectures with an SL component compared to CON lectures. This observation suggests that the use of the online interactive tool did not inhibit verbal classroom engagements and might have encouraged higher classroom participation via asking questions. Moreover, we found that the number of one-on-one Q\&As was less during SL and CON-SL lectures. We hypothesize that the SL platform was an alternative for these one-on-one interactions, which could be beneficial, specifically in the cases where the lecture time does not allow having one-on-one student-instructor interactions. For future studies, we suggest flipping the SL and $\mathrm{CON}$ lectures to examine the potential impacts of the lecture content/topic on students' engagement.

We found that during CON-SL and SL lectures, in addition to the questions asked verbally in class, several questions were asked through the online platform. This is in line with the results of our survey in which several respondents reported being more comfortable posting questions online compared to verbal communications. The questions posted on SL may represent questions that may not have otherwise been asked without this platform. It is important to recognize that different learners have different needs and providing an alternative communication modality to improve classroom participation of those who are shy and would not have asked questions otherwise.

Survey participants indicated that they were more satisfied with the format of SL lectures. This could be related to several factors, such as being able to easily follow along with the lecture slides on their personal devices, positive effects of SL on their learning, or having higher satisfaction with their engagement during SL lectures. Overall, students were positive about the use of the online platform and suggested the use of this tool in the future and in other courses. We found similar results in our previous study, in which an online interactive platform was used during selected tutorials of the same course in prior years [21].

Survey responses provide evidence that students' participation in polls improved their engagement in the classroom. This is aligned with the findings of a previous study in which the use of response cards contributed to higher classroom engagement [22]. Although the course instructor had to purchase a monthly license to access SL, this tool was free for students to use. In this regard, the advantage of SL compared to iClickers was highlighted in students' comments. It is important to note that the cost of purchasing iClickers has been a common concern among students [23]. Although the instructor had to spend some time prior to the lecture to prepare additional polls and annotating slides, the use of this tool, unlike iClickers [13], did not require additional set-up time during the lecture and did not cause a major interruption in the flow of the lecture presentation.

Several students used the SL platform during the five selected lectures, however, the frequency of using this tool dropped throughout the term. This could be associated with an overall reduction in students' engagement throughout the term (e.g., due to an increase in competing course demands or reduced energy) or experiencing technical difficulties (e.g., connectivity issues) during the first trials. Despite the drop rate, we noticed that during all SL lectures, at least one-third of the students were using the online platform and about $24 \%$ remained actively engaged with the tool (e.g., participating in polls).

Several technical and logistical considerations should be made to improve the effectiveness of using this tool in the future. As an example, students mentioned that the use 
of this online platform on smartphones could cause some distractions. A similar concern was also reported previously [24]. To overcome this issue, the instructor could encourage students to access the tool via laptops or tablets to avoid potential detractions associated with the use of smartphones. Some software limitations, such as the inability to annotate slides in real-time and presentation of animated objects, were reported to the developer and would make for improvements in future versions of the software. Moreover, to overcome the flow interruption and concerns regarding the time limit, we suggest to implement this method in longer-duration lectures (e.g., 75-minute lectures). Finally, since the findings of this study are limited to relatively small sample size (i.e., survey participants) in a single course section, we encourage the implementation of this method in other large classrooms with similar lecturing format (i.e., conventional PowerPoint presentation style) to obtain further evidence regarding the effectiveness of using this interaction tool.

Finally, considering the instructor's experiences with SL, there were clear benefits, but also some challenges and drawbacks. The single-system design and PowerPoint integration made deploying SL classes straightforward. The creation of presentations and polls, and the administration SL in class, including delivering polls and tracking of student comments, was easy to do without assistance. The analytics recorded by SL, and the ability to access these at a later time, were also valuable. The primary challenge with SL was in having to adapt a presentation style to suit SL. This particular instructor typically used a stylus on a 2-in-1 style laptop to annotate PowerPoint slides in real time during class. This feature is not supported in SL (or the other similar tools), at least at the time of this study, which meant adapting lecture style to use a series of pre-prepared animation builds in PowerPoint. In addition, in one occasion, the network connection was lost mid-lecture which meant the connection to SL was also lost, causing a brief interruption in the class.

\section{CONCLUSION}

In this paper, we examined the impacts of using an online interaction tool on classroom dynamics. Our findings provide support regarding the positive effects of using this tool on students' learning and engagement in course topics. Overall, students were more engaged and motivated to participate in different class activities (e.g., participating in Q\&As). Specifically, having an alternate method for students to post questions beyond speaking up in class and/or using iClickers appeared to be a valuable option.

\section{Acknowledgements}

We would like to thank the University of British Columbia Centre for the Integration of Research, Teaching, and Learning (CIRTL) for providing funding, and Dr. Lacey Samuels, and Jens Vent-Schmidt for providing technical and intellectual support.

\section{References}

[1] C. Chin and J. Osborne, "Students' questions: A potential resource for teaching and learning science," Stud. Sci. Educ., vol. 44, no. 1, pp. 1-39, 2008, doi: 10.1080/03057260701828101.

[2] C. Whitehead and L. Ray, "Using the iClicker classroom response system to enhance student involvement and learning," ICSIT 2010 - Int. Conf. Soc. Inf. Technol. Proc., pp. 284-289, 2010.

[3] B. Nayee, "Why Should We Care About The Gender Difference in Classroom Participation?," SPICE Student Perspect. Institutions, Choices Ethics, vol. 10, no. 1, 2015, [Online]. Available: https://oceanservice.noaa.gov/facts/why-care-aboutocean.html

[4] J. Moffett, J. Berezowski, D. Spencer, and S. Lanning, “An investigation into the factors that encourage learner participation in a large group medical classroom," $A d v$. Med. Educ. Pract., p. 65, 2014, doi: 10.2147/amep.s55323.

[5] M. Y. Abdullah, N. R. A. Bakar, and M. H. Mahbob, "Student's Participation in Classroom:What Motivates them to Speak up?," Procedia - Soc. Behav. Sci., vol. 51, pp. 516-522, 2012, doi: 10.1016/j.sbspro.2012.08.199.

[6] K. A. Rocca, "Student participation in the college classroom: An extended multidisciplinary literature review," Commun. Educ., vol. 59, no. 2, pp. 185-213, 2010, doi: 10.1080/03634520903505936.

[7] C. Fies and J. Marshall, "Classroom response systems: A review of the literature," J. Sci. Educ. Technol., vol. 15, no. 1, pp. 101-109, 2006, doi: 10.1007/s10956-006-0360-1.

[8] J. R. Stowell and J. M. Nelson, "Teaching of Psychology Benefits of Electronic Audience Response Systems on Student Participation , Learning, and Emotion," pp. 253258, 2007, doi: 10.1080/00986280701700391.

[9] D. Filer, "Using technology to increase classroom participation," Nurs. Educ. Perspect., vol. 31, no. 4, pp. 247-250, 2010.

[10] S. G. Ulbig and F. Notman, "Is Class Appreciation Just a Click Away?: Using Student Response System Technology to Enhance Shy Students' Introductory American Government Experience," J. Polit. Sci. Educ., vol. 8, no. 4, pp. 352-371, 2012, doi: 10.1080/15512169.2012.729450.

[11] J. R. Stowell, T. Oldham, and D. Bennett, "Using Student Response Systems (iClicker $\square$ ) to Combat Conformity and Shyness," Teach. Psychol., vol. 37, no. 2, pp. 135-140, 2010, doi: 10.1080/00986281003626631.

[12] T. Kubica, T. Hara, I. Braun, F. Kapp, and A. Schill, "Choosing the appropriate Audience Response System in different use cases," ICSIT 2019 - 10th Int. Conf. Soc. Inf. Technol. Proc., no. July, pp. 88-93, 2019.

[13] A. Hatun Ataş and Ö. Delialioğlu, "A question-answer system for mobile devices in lecture-based instruction: a qualitative analysis of student engagement and learning," 
Interact. Learn. Environ., vol. 26, no. 1, pp. 75-90, 2018, doi: 10.1080/10494820.2017.1283331.

[14] "Interactive presentation software - Mentimeter." https://www.mentimeter.com/ (accessed Feb. 12, 2020).

[15] "Audience Response System For Live Events \& The Classroom | Glisser." https://www.glisser.com/ (accessed Feb. 12, 2020).

[16] "Slido - Audience Interaction Made Easy." https://www.sli.do/ (accessed Feb. 12, 2020).

[17] "Audience Interaction Tool for PowerPoint" SlideLizard." https://slidelizard.com/en (accessed Feb. 11, 2020).

[18] I. Qualtrics, "Qualtrics," Provo, UT, USA, 2019.

[19] I. I. B. M. SPSS, "IBM SPSS statistics for Windows, version 26.0," New York: IBM Corp. 2019

[20] D. Karp and W. Yoels, "The College Classroom: Some Observations on the Meanings of Student Participation.," Sociol. Soc. Res., 1976, Accessed: Feb. 11, 2020. [Online]. Available: https://psycnet.apa.org/record/1977-30474-001.

[21] M. Khalili and P. M. Ostafichuk, "Improving Class Participation by Using an Online Interactive Platform," in Canadian Engineering Education Association (CEEA), 2018.

[22] E. K. Marmolejo, D. A. Wilder, and L. Bradley, "a Preliminary Analysis of the Effects of Response Cards on Student Performance and Participation in an Upper Division University Course," J. Appl. Behav. Anal., vol. 37, no. 3, pp. 405-410, 2004, doi: 10.1901/jaba.2004.37-405.

[23] K. Kenwright, "Clickers in the classroom," TechTrends, vol. 53, no. 1, pp. 74-77, 2009, doi: 10.1007/s11528-0090240-7.

[24] J. Gikas and M. M. Grant, "Mobile computing devices in higher education: Student perspectives on learning with cellphones, smartphones \& social media," Internet High. Educ., vol. 19, pp. 18-26, 2013, doi: 10.1016/j.iheduc.2013.06.002.

\section{APPENDIX A: SURVEYS}

\section{A.1 CON/SL Surveys}

CON/SL-Q1. Please rate your level of engagement and participation in today's lecture.

Very High [5]/ High [4]/ Neither High nor Low [3] / Low [2] / Very Low [1]

CON/SL-Q2. How satisfied are you with your level of engagement and participation in today's lecture?

Very dissatisfied [1], Dissatisfied [2], Neither satisfied nor dissatisfied [3], Satisfied [4], Very satisfied [5]

CON/SL-Q3. Please rate how easy you found it to follow today's lecture.

Very difficult [1], Difficult [2], Neither difficult nor easy [3], Easy [4], Very easy [5]

CON/SL-Q4. Please rate how satisfied you were with the format/structure of today's lecture.
Very dissatisfied [1], Dissatisfied [2], Neither satisfied nor dissatisfied [3], Satisfied [4], Very satisfied [5]

CON/SL-Q5. [Optional] You can use the space below to name some of the possible inhibiting and/or promoting factors for asking/answering questions in a lecture.

CON/SL-Q6. [Optional] You can use the space below to comment on what could be changed/improved about the format/structure of the lectures to enhance your level of participation in the classroom.

\section{A.2 FIRST-/SECOND-HALF Surveys}

F/S-Q1. Please rate your general level of engagement and participation in MECH 326 lectures in the [first/second] half of the term.

Very High [5]/ High [4]/ Neither High nor Low [3] / Low [2] / Very Low [1]

F/S-Q2. How satisfied are you with your engagement and participation in MECH 326 lectures in the [first/second] half of the term?

Very dissatisfied [1], Dissatisfied [2], Neither satisfied nor dissatisfied [3], Satisfied [4], Very satisfied [5]

F/S-Q3. Please rate your overall satisfaction regarding your understanding of the course in the [first/second] half of the term

Very dissatisfied [1], Dissatisfied [2], Neither satisfied nor dissatisfied [3], Satisfied [4], Very satisfied [5]

F/S-Q4. Please indicate how comfortable you were with verbally asking/answering questions during the lectures in the [first/second] half of the term.

Very uncomfortable [1], Uncomfortable [2], Neither comfortable nor uncomfortable [3], Comfortable [4], Very comfortable [5]

F/S-Q5. Please indicate how comfortable you were with posting questions/answers via the online platform (SlideLizard) used during some lectures in the [first/second] half of the term.

Very uncomfortable [1], Uncomfortable [2], Neither comfortable nor uncomfortable [3], Comfortable [4], Very comfortable [5]

F/S-Q6. Please indicate how you felt the use of the online tool (SlideLizard) impacted your learning of course topics.

Extremely negative impact [1], Negative impact [2], Neither negative nor positive impact [3], Positive impact [4], Extremely positive feedback [5] 
F/S-Q7. Please indicate whether you would recommend the use of the SlideLizard online platform in future in MECH 326 and/or in other courses.

Strongly disagree [1], Disagree [2], Neither agree nor disagree [3], Agree [4], Strongly agree [5]

F/S-Q8. [Optional] What would you say were the greatest benefits of the SlideLizard online platform that was used in some lectures?

F/S-Q9. [Optional] What would you say were the greatest drawbacks of the SlideLizard online platform?

F/S-Q10. [Optional] Please use this space if you have any other comments or feedback. 